
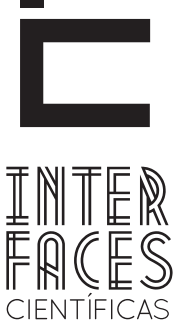

SAÚDE E AMBIENTE

ISSN IMPRESSO 2316-3313

ISSN ELETRÔNICO 2316-3798

DOI - 10.17564/2316-3798.2015v4n1p9-17

\title{
O HOSPITALÉ O LUGAR DA SAÚDE? A PSICOLOGIA DA SAÚDE FRENTE AO PROCESSO SAÚDE-DOENÇA
}

Dafne Ceres Silva ${ }^{1}$

\section{RESUMO}

Este trabalho discute a inserção da Psicologia no ambiente hospitalar e especificamente, a atuação da Psicologia da Saúde frente ao processo saúde e doença. Destacamos o surgimento do hospital e as relações de poder/saber suscitadas no seu interior. Abordamos o processo de adoecimento sob a perspectiva da Saúde Coletiva, considerando-o como um processo vinculado às condições do meio e baseado na multifatorialidade. Da mesma forma, analisamos a adoção do modelo biomédico como paradigma para a inserção da psicologia no ambiente hospitalar. Utilizamos a visão integral e
José Rodrigues Rocha Junior

o modelo biopsicossocial utilizado pela Psicologia da Saúde para discutir a atuação do psicólogo nas instituições de saúde. Em Face da principal discussão sobre o saber fazer do psicólogo da saúde nas instituições de saúde, tentaremos ser propositivos quanto às novas perspectivas para a Psicologia da Saúde no ambiente hospitalar.

\section{PALAVRAS-CHAVE}

Hospital. Psicologia da Saúde. Modelo Biomédico. Modelo Biopsicossocial. Processo Saúde-doença. 


\section{ABSTRACT}

This paper discusses the introduction of Psychology in the hospital environment and specifically the work of the Health Psychology against the health and disease. We highlight the hospital's appearance and relationships of power / knowledge raised inside. We approach the process of falling ill from the perspective of public health, considering it as a process linked to environmental conditions and based on the multifactorial. Likewise, we analyze the adoption of the biomedical model as a paradigm for psychology insertion in the hospital. We use the comprehen- sive vision and the biopsychosocial model used by the Health Psychology to discuss the psychologist in health institutions. In the main discussion on the knowledge of the health psychologist in health institutions face, we try to be purposeful about the new perspectives for Health Psychology in the hospital.

\section{KEYWORDS}

Hospital. Health Psychology. Biomedical Model. Biopsychosocial Model. Health-Disease Process.

\section{RESUMEN}

Este artículo discute la inserción de la Psicología en el ámbito hospitalario y en concreto, el papel de la psicología de la salud en el proceso de salud y enfermedad. Resaltamos el surgimiento del hospital y las relaciones de poder/conocimiento planteadas en su adentro. Abordamos el proceso de la enfermedad desde la perspectiva de la Salud Colectiva, considerándolo como un proceso vinculado a las condiciones ambientales y con base al multifactorial. Del mismo modo, se analiza la adopción del modelo biomédico como paradigma para la integración de la psicología en el ámbito hospitalario. Utilizamos la visión integral y el modelo biopsicosocial utilizado por la Psicología de la Salud para discutir el papel del psicólogo en las instituciones de salud. Delante de la discusión principal sobre la experiencia del psicólogo de la salud en las instituciones de salud, nos convertimos a ser propositivos por las nuevas perspectivas para la Psicología de la Salud en el ámbito hospitalario.

\section{PALABRAS CLAVE}

Hospital. Psicología de la Salud. Modelo biomédico. Modelo Biopsicosocial. Proceso Salud-enfermedad. 


\section{INTRODUÇ̄̃O}

Ao adotar uma perspectiva terapêutica, o ambiente hospitalar irá requerer a intervenção de profissionais das mais diversas áreas, a fim de melhor apreender o processo saúde-doença. 0 ambiente hospitalar então é composto de uma gama de profissionais, cujas áreas de atuação não estão restritas à área de saúde, a exemplo do serviço social. Além dos profissionais que atuam no ambiente hospitalar, também, se configuram como atores, os indivíduos que se servem dos serviços oferecidos no hospital, se estendendo ainda essa atuação para os familiares desses que são ditos convencionalmente "pacientes".

Cada um desses atores representa um olhar que é lançado sobre o processo saúde-doença. 0 que temos então? Vários olhares a partir de diversas perspectivas, que se constituem não apenas da ciência, como do senso comum; da teoria e da prática; do singular e particular, do plural e público; olhares de agora com olhos de ontem. Considerando que os conceitos teóricos são construídos paulatinamente, a partir de uma prática desenvolvida ao longo do tempo; e que, condensam no hoje, ideias construídas em tempos anteriores. Portanto, dessas afirmações e indagações, emerge, a questão dos conceitos saúde e doença.

Consonante afirma Bernardes, Guareschi e Medei$\operatorname{ros}(2005$, p. 264):

Desse modo, quando elegemos determinado objeto,
como, neste caso, a saúde, não o fazemos de qualquer
lugar - nós o tomamos a partir daquele território no
qual aprendemos a olhá-lo. A saúde, então, passa a
ser uma realidade que opera determinados processos
existenciais ao mesmo tempo em que só é possível a
partir de determinadas operações, de certos campos
de conhecimento, nos quais ocorrem transportes, tra-
duções, interpretações, isto é, formas de objetivação
que, ao darem sentido a determinados fenômenos,
produzem modos de nos relacionarmos conosco.

Esses conceitos são construções anteriores ao ambiente hospitalar, antecedem até mesmo os próprios profissionais de saúde, ou ainda, aqueles de quem habitualmente denominam-se "doentes" e "sãos". Esse olhar sob a lente do "zeitgeist" é imprescindível, considerando que: "[...] o conhecimento da história pode trazer ordem à desordem e produzir sentido a partir do caos; permitindo enxergar o passado com mais clareza e explicar o presente." Nas palavras de Schultz e Schultz citado por Chiattone (1992, p. 20 APUD CAMON, 2006, p. 80).

Contudo, é inegável a influência que o ambiente hospitalar detém sobre esses conceitos, uma vez que os profissionais de saúde ali referidos são tidos como os detentores do saber/poder capaz de identificar e normatizar a saúde e a doença. Analogamente às palavras de Focault (1966), diríamos que o funcionamento estatutário age como um filtro sobre o grito oriundo da dor do individuo, que vivencia o processo saúde-doença; permitindo que se ouça apenas a parte inteligível e ininteligível do discurso. A forma grito da dor teria se tornado inacessível devido ao filtro do saber instituído. Não há como descrever a dor do outro, apenas aquele que sente e vivencia a dimensão de sua própria dor. Numa tentativa de conceituar a dor, iremos ser confrontados por seu caráter subjetivo.

A dor é um detalhamento de subjetividade em binômio indivisível com a objetividade da própria fisiologia humana. E isso, por si, já determina padrões de comportamentos que não serão estanques, nem sequer tangíveis de serem enquadrados em qualquer lógica que não contemple essa subjetividade (CAMON, 2012, p. 16)

Todos os métodos de observação cientificamente construídos não têm sido suficientes para construir caminhos de acesso à dor, ao sofrimento desse outro do qual a ciência clássica positivista com caráter reducionista, determinista ousa saber e dizer. Porque para tanto, é preciso categorizar até mesmo a dor e o sofrimento, mas a forma grito da dor está acessível por intermédio da premissa da individuação; da compreensão de que é preciso ouvir o grito de dor daquele que a sente e vivencia, e somente este, pode saber de sua dor.

Consonante Camon (2012, p. 23):

Não existe, então, espaço para o determinismo científico com sua avalanche de resultados científicos, pois o so- 
frimento humano só pode ser auscultado por outra alma acolhedora. E isso é algo do qual não podemos abrir mão se quisermos de fato nos aproximar da dor humana e do desesperado modo verdadeiramente humano.

Esse filtro agiria, também, sobre os conceitos de saúde e doença, considerando indistintamente, aquilo que ora os constituem comum, ora particular. Ainda segundo Focault (1966): 0 ato de conhecer e sujeitar e de saber e comandar são coisas que estão intimamente ligadas.

No âmago desse imaginário coletivo consta ainda o ambiente hospitalar legitimado enquanto entidade capaz de abrigar a doença e devolver ao ser o estado de saúde para o mundo exterior.

\section{HOSPITAL: HOSPEDAR A DOENÇA OU CURAR O DOENTE?}

O ambiente hospitalar suscita inúmeros questionamentos, dada à diversidade de sua demanda, ao lidar constantemente com o processo saúde-doença. Face ao exposto, nos ocupamos em compreender as várias facetas do ambiente hospitalar. Como surge e com quê finalidade são criados os hospitais; e, como esse ambiente destinado a "hospedagem", como sugere sua própria denominação, evoluiu ao longo do tempo, alcançando o status de terapêutico e como uma das grandes instituições abarcadas pela sociedade.

A partir da análise da história dos hospitais, desde a sua criação até a contemporaneidade, observamos que os hospitais sofreram significativas transformações; tanto em sua estrutura, quanto em relação à sua finalidade.

Os hospitais surgem primeiramente, pautados pelo assistencialismo e dirigidos por leigos religiosos. Destacamos que a figura do médico no ambiente hospitalar não surge paralelamente a sua criação, a medicina hospitalar se desenvolve em decorrência da evolução desse modelo de hospital inicial. De acordo com Foucault (2012), a ideia de hospital como instrumento terapêutico é relativamente recente, criado no final do século XVIII.
Apenas em meados de 1780, tornar-se-ia consenso o ideal de hospital como instrumento destinado a curar. 0 mesmo autor ainda afirma que anteriormente, desde a Idade Média, o que se tinha era um hospital destinado ao assistencialismo, com funções subjacentes de separação e exclusão. Nesse sentido, Foucault (2012, p.175) afirma ainda: "Diziase correntemente, nesta época, que o hospital era um morredouro, um lugar onde morrer. E o pessoal hospitalar não era fundamentalmente destinado a realizar a cura do doente, mas a conseguir sua própria salvação".

Os hospitais surgem com uma função assistencialista e de exclusão/separação. 0 objetivo era dar assistência aos "doentes", leia-se pobres, ao tempo em que os mesmos eram excluídos da sociedade. Ora, o pobre como tal, deve ser assistido; e o pobre doente representa um perigo para sociedade porque é portador de doença de possível contágio. Por isso, Focault (2012), descreve como personagem ideal do hospital, até o século XVIII, o pobre que está morrendo e precisa de salvação e não o doente que necessita de cura. Tendo em vista que o hospital não tem como objetivo primordial, a cura do doente, aquém da figura do médico, aqueles que compunham a equipe hospitalar, eram religiosos ou leigos, pessoas dispostas a fazerem uma obra de caridade.

Vê-se, assim, que nada na prática médica dessa época permitia a organização de um saber hospitalar, como também nada na organização do hospital permitia intervenção da medicina. As series hospital e medicina permaneceram, portanto, independentes até meados do século XVIII (FOCAULT, 2012, p.176)

Os objetivos do hospital foram repensados a partir da análise dos efeitos nocivos daquele modelo de hospital inicialmente instaurado na Idade Média. 0 hospital servia como elemento de segregação, evitando que as doenças se proliferassem, excluindo os doentes do convívio social. A função terapêutica advém com a disciplinarização do ambiente hospitalar, isto porque o objetivo inicial era evitar que o hospital fosse responsável por suscitar doenças e a contaminação do local onde estava situado na cidade. A medicalização do hospital não surge para curar, mas para assegurar a disciplina hospitalar. 


\section{A PSICOLOGIA DA SAÚDE FRENTE AO PROCESSO E DOENCWA NO AMBIENTE HOSPITALAR}

Assim como ocorreu com a medicina, que medicalizou o hospital, este último, também, teve que ser psicologizado, para que a psicologia pudesse estar inserida no ambiente hospitalar. Cabe destacar que o caminho para a construção de uma psicologia no contexto hospitalar, é feito a partir das análises empíricas, assim como também ocorreu com a medicina. De fato, as observações advindas das experiências que insurgem da inserção da psicologia no ambiente hospitalar, tornar-se-iam a matéria-prima para a constituição de uma prática psicológica voltada para as minúcias do contexto hospitalar.

A prática médica, até então concebida fora dos hospitais, não era suficiente para atender as novas demandas oriundas de o ambiente hospitalar. 0 médico, empiricamente, por meio de sua inserção no hospital, foi construindo paulatinamente uma clínica médica hospitalar. Do mesmo modo, a psicologia clínica, entendida como psicologia psicoterapêutica, realizada fora do hospital não fora por si só suficiente para construção de uma psicologia no contexto hospitalar. Apesar de inicialmente, de forma equivocada, conceber a psicologia psicoterapêutica transportada para dentro do hospital como uma legítima psicologia hospitalar, ou melhor, denominando, psicologia clínica da saúde; a dinâmica da realidade hospitalar iria reivindicar conceitos teórico-práticos próprios.

A inicial transposição do modelo clínico psicoterápico para as instituições de saúde suscita inúmeras questões relativas à atuação do psicólogo no ambiente hospitalar. Conforme Chiattone (APUD CAMOM, 2006, p. 94):

\footnotetext{
Todavia, ao transpor esse modelo para as instituições de saúde, o psicólogo defronta-se com dificuldades inerentes à própria demanda institucional e à própria limitação de sua formação; mas, mesmo assim, nem sempre busca ampliar sua tarefa, mantendo a tendência de atividades individuais de consultas em consultórios, desprezando a participação em ações integradas às equipes.
}

O fato é que, o estabelecimento de uma rotina de atendimentos individualizados, remetendo à instalação do consultório do psicólogo no hospital, não concretizaria a inserção da psicologia no ambiente hospitalar. A psicologia, assim posta, estaria reduzida a função de apêndice dentro do hospital. Não basta estar dentro para estar inserido, este último requer uma interação e integração entre as diversas partes, no caso a psicologia estabelecendo relação com todo o ambiente hospitalar.

O processo saúde e doença no contexto hospitalar, demanda da psicologia, não apenas um fazer por, mas um fazer com. 0 que implica em uma atuação que acontece em conjunto com as demais áreas de conhecimento existentes no hospital. Além de propor uma análise crítica da inserção da psicologia nas instituições de saúde, o objetivo não é categorizar em certo ou errado, mas compreender as condições e as correlações de força que pautaram e originaram os conceitos e práticas adotadas.

É possível assim, observarmos que o campo de atuação profissional do psicólogo vem ampliando-se e novas áreas de atuação tem-se desenhado ao lado daquelas mais tradicionais, como fruto do próprio movimento da sociedade e do mercado de trabalho. Não obstante, a prática de o psicólogo no ambiente hospitalar é considerada uma dessas áreas mais recentes de atuação, e assim como ocorreu com a constituição do campo de saber da psicologia, a atuação do psicólogo no contexto hospitalar herdou a pluralidade própria da psicologia. Comungamos da seguinte preocupação de que o profissional ocupado em garantir mais esse espaço de atuação, desvie-se de seus objetivos, que perpassam principalmente, pela assistência psicológica aos pacientes.

Conforme Mancebo citado por Chiattone (1997, p. 21 APUD CAMON, 2009, p. 81):

[...] se sabe que os necessários embates no campo epistemológico não foram tratados com a devida atenção, na medida em que a corporação, em seus momentos definitórios, optou pela busca de soluções acomodatícias, à justificação de projetos de grupos, que visavam muito mais à manutenção do status já atingi- 
do, por alguns de seus membros, do que propriamente pelo enfrentamento teórico.

Sob todas essas considerações e questionamentos, realizam-se os primeiros ensaios de uma prática psicológica no ambiente hospitalar. 0 trabalho dos psicólogos nas instituições de saúde se desenvolve inicialmente, com a proposta de integrar a psicologia na prática médica. 0 modelo cartesiano adotado pela medicina é o modelo que também irá pautar esse início de atuação do psicólogo, reafirmando a dicotomia mente e corpo, o objetivo é voltado principalmente para a humanização do atendimento (ROCHA JUNIOR e MARTINS, 2001).

Quando reconhecemos como legítima a aplicação da terminologia psicologia da saúde, ao invés de psicologia hospitalar, estamos apenas constatando aquilo que é a expressão da realidade que nos intima a não mais pensarmos apenas em formas de tratar a doença; mas, sobretudo, formas de tratarmos de saúde. Para tanto, dizemos de uma psicologia que atua pela saúde e para a saúde, dentro e/ou fora dos hospitais; uma psicologia muito menos ocupada com o espaço de atuação, e muito mais ocupada com a própria atuação.

A psicologia da saúde inserida no ambiente hospitalar possibilitará o descortinamento do véu institucional que pode limitar as ações, restringindo-as ao saber que se opera in loco, desconsiderando que os sujeitos que passam pela instituição são reprodutores e produtores de saber, dentro ou fora da instituição. Mais do que mera escolha por qual seja a terminologia mais adequada, o que nos compromete é pensarmos a respeito da necessidade de reconhecermos uma psicologia da saúde, pois não seria esse o propósito de toda instituição de saúde? Propor saúde.

A Psicologia da Saúde, como o próprio termo sugere, não está limitada ao hospital, por isso mesmo sua atuação abrange todos os níveis de prevenção em saúde e a promoção da saúde. É importante ressaltar, que acompanhando as transformações sociais, tecnológicas e econômicas, as ações destinadas à saúde também sofreram modificações.
A globalização é um exemplo das grandes transformações ocorridas no início do século XX, que desencadeou uma profusão das informações, com o avanço das telecomunicações e a implantação de redes de informática. As informações são compartilhadas de forma cada vez mais rápida e com um maior alcance. Essa universalização da informação atribui uma nova dimensão para adoção de práticas destinadas a saúde.

Por meio da mídia, a saúde, um problema humano e existencial, pode ser compartilhada por todos os segmentos da sociedade. Para esses segmentos sociais, a saúde e a doença envolvem uma complexa interação entre os aspectos físicos, psicológicos, sociais e ambientais da condição humana e seus significados, exprimindo uma relação que perpassa o corpo individual e social, o ser humano enquanto ser total. Portanto, a saúde e a doença são categorias que trazem uma carga histórica, cultural, política e ideológica. Essa revisão dos valores culturais está sendo acompanhada de profundas alterações (ROCHA JUNIOR; MARTINS, 2001, p. 36)

Outro dado importante é o aumento da expectativa de vida, a sociedade tem o prolongamento da vida garantido por meio não apenas da cura de determinadas doenças; bem como, por intermédio da possibilidade de melhoria da qualidade de vida e cuidado aos pacientes acometidos de patologias para as quais não há cura ou ainda aqueles que estão no momento final da vida. Nesse último caso, os chamados cuidados paliativos. Nesse sentido:

Estudos do IBGE mostram que entre 1901 e 2000, a população brasileira passou de 17,4 para 169,6 milhões de pessoas, e a expectativa de vida de um homem brasileiro subiu dos 33,4 anos em 1910 para os 64,8 anos em 2000. Entretanto, junto com o prolongamento da vida, os profissionais de saúde começaram a perceber que mesmo não havendo cura, há uma possibilidade de atendimento, com ênfase na qualidade de vida e cuidados aos pacientes, por meio de assistência interdisciplinar, e da abordagem aos familiares que compartilham deste processo e do momento final da vida - os cuidados paliativos. (HERMES; LAMARCA, 2013, p. 2578). 
A sociedade globalizada requer ações destinadas à saúde que agora são formuladas por todos os segmentos dessa sociedade, tendo a contribuição de diferentes áreas, não podendo mais ficar limitada ao âmbito do modelo clínico/assistencialista, nem ao espaço do hospital. A universalização da saúde passa então por uma concepção de saúde coletiva. Nesse sentido, o que se propõe é uma visão integrada do processo saúde/doença, que implicará numa atuação embasada por conhecimentos e práticas interdisciplinares. A psicologia da saúde, busca a interdisciplinaridade ao utilizar conhecimentos das ciências biomédicas, da Psicologia Clínica e da Psicologia Social-comunitária; adotando o modelo biopsicossocial (BORNHOLDT e CASTRO, 2004).

A Psicologia da Saúde foi assim definida por Matarazzo (1980, p. 815 APUD ROCHA JUNIOR e MARTINS, 2001, p. 37):

[...] o conjunto de contribuições educacionais, científicas e profissionais específicas da Psicologia para a promoção e manutenção da saúde, prevenção e tratamento das doenças, na identificação da etiologia e diagnósticos relacionados à saúde, à doença e às disfunções, bem como no aperfeiçoamento do sistema de políticas da saúde.

O saber fazer da psicologia da saúde no ambiente hospitalar tem como característica fundamental o modelo biopsicossocial e recobra a visão sanitarista, em detrimento a visão meramente assistencialista. Isso importa em dizer que o psicólogo da saúde, atuando no ambiente hospitalar ou em qualquer outra instância, perseguirá a promoção e prevenção da saúde, adotando práticas que ultrapassam o assistencialismo e potencializam o papel de métodos psicoeducativos, objetivando conferir ao paciente, autonomia durante o processo saúde-doença. 0 "paciente" reconhecido, também, como "agente" de saúde. Não obstante, destacamos o papel desses diversos agentes, na construção de uma saúde pública.

Na literatura científica, um dos conceitos mais aludidos, no campo da saúde é aquele enunciado, em 1920, por Winslow (1920), em que ele diz que Saúde Pública

\begin{abstract}
é a ciência e a arte de evitar a doença, prolongar a vida e promover a saúde física e mental, e a eficiência, através de esforços organizados da comunidade, visando o saneamento do meio, o controle das infecções comunitárias, a educação do indivíduo nos princípios da higiene pessoal, a organização de serviços médicos e de enfermagem para o diagnóstico precoce e o tratamento da doença e o desenvolvimento dos mecanismos sociais que assegurarão a cada pessoa na comunidade o padrão de vida adequado para a manutenção da saúde, organizando estes benefícios de tal modo que cada indivíduo esteja em condições de gozar de seu direito natural à saúde e à longevidade. Destacar-se, ser a saúde pública o esforço organizado da sociedade para ampliar as possibilidades de os indivíduos poderem gozar as melhores condições possíveis de saúde. (ALMEIDA, 2013, p. 5).
\end{abstract}

A Psicologia da Saúde abrange a necessidade de pensar formas de compreender e enfrentar o processo saúde-doença, considerando as particularidades sociais historicamente construídas. Enxergar não apenas a patologia, ou o doente, mas a observação de que cada um dos elementos são construções que estão inter-relacionadas; e, são determinantes e determinadas, a partir da interação que se desenvolve entre ambos no processo saúde-doença.

Consonante Susser (1973) citado por Sebastiani:

\begin{abstract}
$\mathrm{Na}$ atualidade ocorre à tendência a encarar a doença, em sentido lato, como fenômeno que inclui não apenas a participação individual, mas, também, e necessariamente, a social. A doença ("disease") corresponderia ao processo fisiopatológico determinante do estado de disfunção, e conseqüentes desabilidade funcional e deficiência do indivíduo. A enfermidade (“illness") seria concernente ao estado subjetivo do indivíduo afetado e decorrente da própria conscientização. E, a que se pode chamar anormalidade ("sickness") seria pertinente ao "papel de doente" ("sick role") que a pessoa assume na sociedade, ou seja, à correspondente disfunção social e que, portanto, afeta o seu relacionamento com os demais indivíduos normais. (SEBASTIANI APUD CAMON, 2006, p. 201).
\end{abstract}

Atualmente, reconhecemos que o modelo biomédico ainda é o modelo adotado no ambiente hospitalar, fortalecendo a verticalização no funcionamento do hospital, enquanto estrutura institucional. 0 profis- 
sional psicólogo precisa estar bastante cônscio do seu saber e saber fazer, para não reforçar ainda mais o distanciamento entre os saberes e, para que, o psicólogo não se torne um assistente do médico (CAMON, 2009).

A Psicologia da Saúde defende a interdisciplinaridade e entende que é possível que o saber médico e o saber psicológico sejam complementares dentro do modelo biopsicossocial. Considerando que: "Nesse sentido, evidencia-se a importância da integração do profissional psicólogo com outros profissionais da área da saúde, visto que são diversos os fatores relacionados no processo saúde-doença" (CALVETTI, MULLER; NUNES, 2007, p. 708).

Essa verticalização reconhecida dentro do ambiente hospitalar ocasiona ainda, a profusão de diversas considerações sobre aquilo que deve ser considerado como saber fazer do psicólogo inserido no hospital. A atuação de o psicólogo no ambiente hospitalar e a definição quanto àquilo que deve ser considerado como demanda específica para a Psicologia suscitam opiniões diversas. As divergências ocorrem entre os demais profissionais, principalmente médicos e psicólogos; bem como, entre os próprios psicólogos.

\section{CONSIDERACÕES FINAIS: NOVAS PERSPECTIVAS POR MEIO DA PSICOLOGIA DA SAÚDE NO AMBIENTE HOSPITALAR}

Como observamos, a atuação da Psicologia no ambiente hospitalar urge, por ações concretas que visem delimitar e definir a teoria e a prática do psicólogo. Questões tais como: a entrada indiscriminada em hospitais, sem a devida formação especifica para área hospitalar; as diferenças entre os modelos (modelo biomédico $X$ modelo biopsicossocial) que coexistem no mesmo local de atuação; a ausência de um paradigma claro para a psicologia, resultando na dificuldade de se estabelecer objetivos claros na tarefa (CAMON, 2009). São questões prementes de análise crítica, que servirá como condutor para novas perspectivas para a Psicologia da Saúde no ambiente hospitalar.
A Psicologia da Saúde adotando o modelo biopsicossocial proporá uma visão integral do processo saúde-doença e defenderá a interdisciplinariedade como forma de alcançar todas as variáveis psicológicas, presentes na manutenção da saúde, no desenvolvimento de doenças e nos comportamentos associados. Diferentemente do modelo biomédico, que eminentemente reducionista e materialista, visa atender o processo saúde-doença a partir apenas de uma concepção assistencialista-curativa; a Psicologia da Saúde propõe discutir não apenas a doença, mas, sobretudo, a saúde.

As transformações ocorridas na sociedade ao longo do tempo determinaram novas necessidades diante do processo saúde-doença, nossa preocupação esta no tocante ao atendimento dessas necessidades. Inicialmente ocupados com a humanização de o ambiente hospitalar, preocupados com a despersonalização do paciente, a relação médico-paciente, o psicólogo no ambiente hospitalar não pode deixar de questionar: a ausência de atendimento aos pacientes, devido à insuficiência de profissionais; a espera prolongada por atendimento, por vezes tendo que ignorar a urgência; a sobrecarga na jornada de trabalho imposta aos profissionais que atuam no ambiente hospitalar; entre outros. Essas questões relacionadas ultrapassam 0 conhecimento médico da doença e da saúde, mas nem por isso, podem ser desconsideradas e menosprezadas em sua influência sobre o processo saúde-doença.

As novas perspectivas propõem um caminho de integralização, um entendimento de que o conhecimento não deve ser particularizado, uma visão do todo para não perder a noção das partes. Ao invés de estarmos discutindo o óbvio que são as diferenças entre subjetivo e objetivo, mente e corpo; estaremos imbuídos de um "novo" paradigma que vai além do "científico".

Um novo paradigma que não desconhece as contradições socioeconômicas e culturais que atuam constantemente sobre o processo saúde-doença, que irá subsidiar teorias e práticas psicológicas voltadas para a realidade do que acontece aqui e agora e para as realidades anteriores que reverberam atualmente. Mais do que um compromisso científico, assumiremos 
um compromisso ético e social. Ao invés de trabalhar separadamente, esse "novo" paradigma propõe unir, aglutinando novos e velhos conceitos em prol da saúde individual e coletiva.

\section{REFERÊNCIAS}

ALMEIDA, N. D. A saúde no Brasil, impasses e desafios enfrentados pelo Sistema Único de Saúde: SUS. Rev. Psicol. Saúde, v.5, n.1, 2013. p.1-9.

BERNARDES, A. G.; GUARESCHI, Neuza M. F. e MEDEIROS, P. F. O Conceito de Saúde e suas Implicações nas Práticas Psicológicas. Psicologia: Teoria e Pesquisa, v.21, n.3, set-dez. 2005. p.263-269.

BORNHOLDT, E.; CASTRO, E. K. Psicologia da Saúde X Psicologia Hospitalar: Definições e Possibilidades de Inserção Profissional. Psicologia, ciência e profissão, 24 (3):48-57, 2004.

CALVETTI, P.U., MULLER, M. C. e NUNES, M. L. T. Psicologia da Saúde e Psicologia Positiva: Perspectivas e Desafios. Psicologia, Ciência e Profissão, 27 (4):706-717, 2007.

CAMOM, V. A. A. (Org.). Psicologia da saúde: um novo significado para a prática clinica. São Paulo: Thomson Learning, 2006.
CAMON, V. A. A. Tendências em psicologia hospitalar. São Paulo: Cengage Learning, 2009.

CAMON, V. A. A. (Org.). Psicossomática e a Psicologia da Dor. 2.ed. rev. e amp. São Paulo: Pioneira Thomson Learning, 2012.

CHIAtTONE, H. B. de C. A Significação da Psicologia Hospitalar. In: CAMOM, V. A. A. (Org.). Psicologia da saúde: um novo significado para a prática clinica. São Paulo: Thomson Learning, 2006.

FOCAULT, M. Microfísica do poder. 25.ed. São Paulo: Graal, 2012.

HERMES, H. R.; LAMARCA, I. C. A. Cuidados paliativos: uma abordagem a partir das categorias profissionais de saúde. Ciênc. saúde coletiva, v.18, n.9, 2013. p.2577-2588.

JÚNIOR, R. A.; MARTINS, D. G. Psicologia da saúde e o novo paradigma: novo paradigma? São Paulo, 2001.

SEBASTIANI, R. W. Histórico e Evolução da Psicologia da Saúde numa Perspectiva Latino-Americana. In: CAMOM, V. A. A. (Org.). Psicologia da saúde: um novo significado para a prática clinica. São Paulo: Thomson Learning, 2006. 